\title{
Preparation and Antibacterial Properties of Silver Nanoparticles
}

\author{
Qu Zhencai ${ }^{\mathrm{a}}$, Zhang Yan ${ }^{\mathrm{b}}$, Liu Shiweic and Song Weisheng ${ }^{\mathrm{d}}$ \\ Department of Packaging and Printing, Henan University of Animal Husbandry \& Economy, Henan, \\ China \\ aquzhencai@126.com, b153556920@qq.com, c7557981@qq.com, d821258228@qq.com
}

\begin{abstract}
Keywords: Liquid phase reduction method, Nano-silver powder, Antibacterial properties.
Abstract. The nano silver powder was prepared by liquid phase reduction of silver nitrate solution with ascorbic acid $\left(\mathrm{C}_{6} \mathrm{H}_{8} \mathrm{O}_{6}\right)$ as the reducing agent and polyethylene glycol 200 as the dispersant. Through a $\mathrm{L}_{9}\left(3^{4}\right)$ orthogonal project, the optimum process conditions were determined as follows: the concentration of $\mathrm{AgNO}_{3}$ was $20 \mathrm{mg} / \mathrm{mL}$, the amount of polyethylene glycol 200 was $10 \mathrm{~mL}$, and $\mathrm{n}\left(\mathrm{C}_{6} \mathrm{H}_{8} \mathrm{O}_{6}\right) / \mathrm{n}\left(\mathrm{AgNO}_{3}\right)$ was $1: 3$, the reaction temperature was $60{ }^{\circ} \mathrm{C}$. Under these conditions, evenly dispersed and high purity nano-silver powder can be prepared. The average particle size of the silver nanoparticles was less than $10 \mathrm{~nm}$ by Malvern laser particle size analyzer, TEM and XRD. The antibacterial activity of nano silver powder was tested, and the results showed that when the concentration of nano-silver powder was $10 \mathrm{ug} / \mathrm{mL}$, the inhibition zone of E. coli could reach $15 \mathrm{~mm}$, and the antibacterial effect was significant.
\end{abstract}

\section{Introduction}

With the rapid development of science and technology, nano-materials have been widespread concern because of its high efficiency, environmental protection, sustainability and other characteristics. Nano-silver powder has the advantages of large surface area, high chemical activity and remarkable volume effect, and has been used for a long time [1]. It is reported that nano-silver powder can kill hundreds of bacteria in a few minutes, and will not cause bacterial resistance. At present, the preparation of nano-silver in general can be divided into physical, chemical and biological law three categories [2]. Physical methods are evaporation condensation, ion sputtering and mechanical grinding method, there are large investment in equipment, production costs and other shortcomings. Chemical methods are the most commonly used preparation method of nano-silver, including reducing agent reduction method, microemulsion method, radiation synthesis method, photochemical reduction method and electrochemical method. Biological methods include microbial enzyme catalyzed and non-enzymatic reduction of two methods, with the characteristics of environmental safety, it will be the future direction of nano-silver preparation technology [3].

In this paper, nano-silver powder was prepared by liquid phase reduction of silver nitrate with a certain biological activity of ascorbic acid as a reducing agent. The optimum conditions for preparation of nano-silver powder were determined by orthogonal experiment, and the antibacterial properties of nano-silver powder were tested.

\section{Experiments}

Experiment Equipment. Apparatus: Digital temperature control electric mixer (JJ-3), Changzhou Runhua Electric Co., Ltd.; Ultra-clean workstations, Shanghai Tianheng medical equipment company; Transmission Electron Microscope (S-550), Hitachi, Japan; Malvern Mastersizer 2000, Malvern, UK; Electric centrifuge (800), Changzhou Australia and China Instrument Co., Ltd.; Ultrasonic cell grinder (JY96-II), the New Chi Biological Technology Co., Ltd.; Thermostat water bath (HH-1), Changzhou Australia and China Instrument Co., Ltd.; Electronic balance (AL204), METTLER TOLEDO Instrument Co., Ltd.

Materials: Polyethylene glycol 200 (AR), Sinopharm Group Chemical Reagent Co.; Ascorbic acid (AR), Hunan Huihong Reagent Co., Ltd.; $\mathrm{AgNO}_{3}$ (AR), Hunan High Purity Chemical Reagent Factory; Peptone (BR), Sinopharm Group Chemical Reagent Co.; Beef paste (BR), Hangzhou 
Microbial Reagent Co., Ltd.; $\mathrm{NaCl}$ (AR), Shanghai test four Hewei Chemical Co., Ltd. Ammonia (AR), Guangzhou East Red Chemical Plant; Ethanol (AR), Guangzhou East Red Chemical Plant; Distilled water, homemade.

Experimental Methods and Procedures. (1) Orthogonal experimental design: According to the design method of orthogonal experiment, the concentration of silver nitrate (A), polyethylene glycol $200(\mathrm{~B}), \mathrm{n}\left(\mathrm{C}_{6} \mathrm{H}_{8} \mathrm{O}_{6}\right) / \mathrm{n}\left(\mathrm{AgNO}_{3}\right)(\mathrm{C})$ and reaction temperature (D) were selected as the main research object. Each factor is given three levels, the $\mathrm{L}_{9}\left(3^{4}\right)$ orthogonal experiment was designed, the influence of all factors on the particle size and morphology of nano-silver powder was studied [4].

(2) Preparation of nano-silver powder: according to the orthogonal table, respectively, a certain amount of $\mathrm{AgNO}_{3}$ powder and ascorbic acid was weighed in different clean beaker, and a appropriate amount of deionized water was added to dub a certain concentration of silver nitrate solution and ascorbic acid solution. According to an orthogonal experiment, an amount of polyethylene glycol 200 was added into the silver nitrate solution and the ascorbic acid solution was added into the mixed solution at a rate of not more than 30 drops per minute in an electric mixer at a rate of $600 \mathrm{r} / \mathrm{min}$. And an appropriate amount of ammonia was dropped into the reaction solution to control the $\mathrm{PH}$ in 10 or so, when the addition was complete, continue to keep stirring for 60 minutes. Finally, the reaction solution was centrifuged 5 times at a speed of $3000 \mathrm{r} / \mathrm{min}$ using an ultrasonic cell pulverizer for 10 minutes each, the supernatant was discarded and the remaining samples were dispersed and stored with ethanol [5].

(3) Characterization and test of nano-silver powder: The size of nano-silver powder was measured by Malvern laser particle size analyzer, and nano-silver powder was characterized by TEM and X-ray diffraction [6].

(4) Antibacterial test of nano-silver powder: $5 \mathrm{~g}$ sodium chloride was taken, and $1000 \mathrm{ml}$ water was added, then $5 \mathrm{~g}$ beef extract and $10 \mathrm{~g}$ peptone was put into the sodium chloride solution to prepare the culture medium of $\mathrm{E}$. coli, the $\mathrm{pH}$ was controlled between 7.2 to 7.6. A certain concentration of nano-silver solution was pipetted on a circular paper with a diameter of $5 \mathrm{~mm}$ and dried under aseptic conditions. The paper was placed on a bacterial dish and placed in a $37{ }^{\circ} \mathrm{C}$ incubator for $24 \mathrm{~h}$, the diameter of the inhibition zone was observed [7].

\section{Results and Discussion}

Orthogonal Experiment. According to the experimental method, the orthogonal experiment table of $\mathrm{L}_{9}\left(3^{4}\right)$ was designed, as shown in Table 1.

Table 1. Given factors and levels

\begin{tabular}{|c|c|c|c|c|}
\hline \multirow{2}{*}{ Levels } & \multicolumn{4}{|c|}{ Factors } \\
\cline { 2 - 5 } & $(\mathrm{A})[\mathrm{mg} / \mathrm{mL}]$ & $(\mathrm{B})[\mathrm{mL}]$ & $(\mathrm{C})$ & $(\mathrm{D})\left[{ }^{\circ} \mathrm{C}\right]$ \\
\hline 1 & 10 & 10 & $1: 2$ & 40 \\
\hline 2 & 20 & 20 & $1: 3$ & 50 \\
\hline 3 & 30 & 30 & $1: 4$ & 60 \\
\hline
\end{tabular}

Table 2. Experimental results of $\mathrm{L}_{9}\left(3^{4}\right)$ orthogonal experiment on nano-silver Powder

\begin{tabular}{|c|c|c|c|c|c|}
\hline NO. & A & B & C & D & Mean size [nm] \\
\hline 1 & 1 & 1 & 1 & 1 & 48.24 \\
\hline 2 & 1 & 2 & 2 & 2 & 32.36 \\
\hline 3 & 1 & 3 & 3 & 3 & 18.67 \\
\hline 4 & 2 & 1 & 2 & 3 & 8.68 \\
\hline 5 & 2 & 2 & 3 & 1 & 25.69 \\
\hline 6 & 2 & 3 & 1 & 2 & 45.56 \\
\hline 7 & 3 & 1 & 3 & 2 & 42.97 \\
\hline 8 & 3 & 2 & 1 & 3 & 20.26 \\
\hline 9 & 3 & 3 & 2 & 1 & 51.85 \\
\hline
\end{tabular}


Orthogonal Experimental Results. According to L9 $\left(3^{4}\right)$ orthogonal test program, with the malvern granularity analysis, the average particle size was as shown in Table 2.

Table 1 and Table 2 show that the best combination of the orthogonal experiments is $A_{2} B_{1} C_{2} D_{3}$, that is, the optimal preparation conditions of the nano-silver powder are: the concentration of $\mathrm{AgNO}_{3}$ was $20 \mathrm{mg} / \mathrm{mL}$, the amount of polyethylene glycol 200 was $10 \mathrm{~mL}, \mathrm{n}\left(\mathrm{C}_{6} \mathrm{H}_{8} \mathrm{O}_{6}\right) / \mathrm{n}\left(\mathrm{AgNO}_{3}\right)$ was 1:3, and the reaction temperature was $60{ }^{\circ} \mathrm{C}$, then the average particle size of $8.67 \mathrm{~nm}$ nano-silver powder can be prepared.

Particle Size Distribution, TEM and XRD Patterns of Silver Nanoparticles. The results of the experiment $\mathrm{A}_{2} \mathrm{~B}_{1} \mathrm{C}_{2} \mathrm{D}_{3}$ were measured by the malvern particle size distribution test, and the results were shown in Fig. 1.

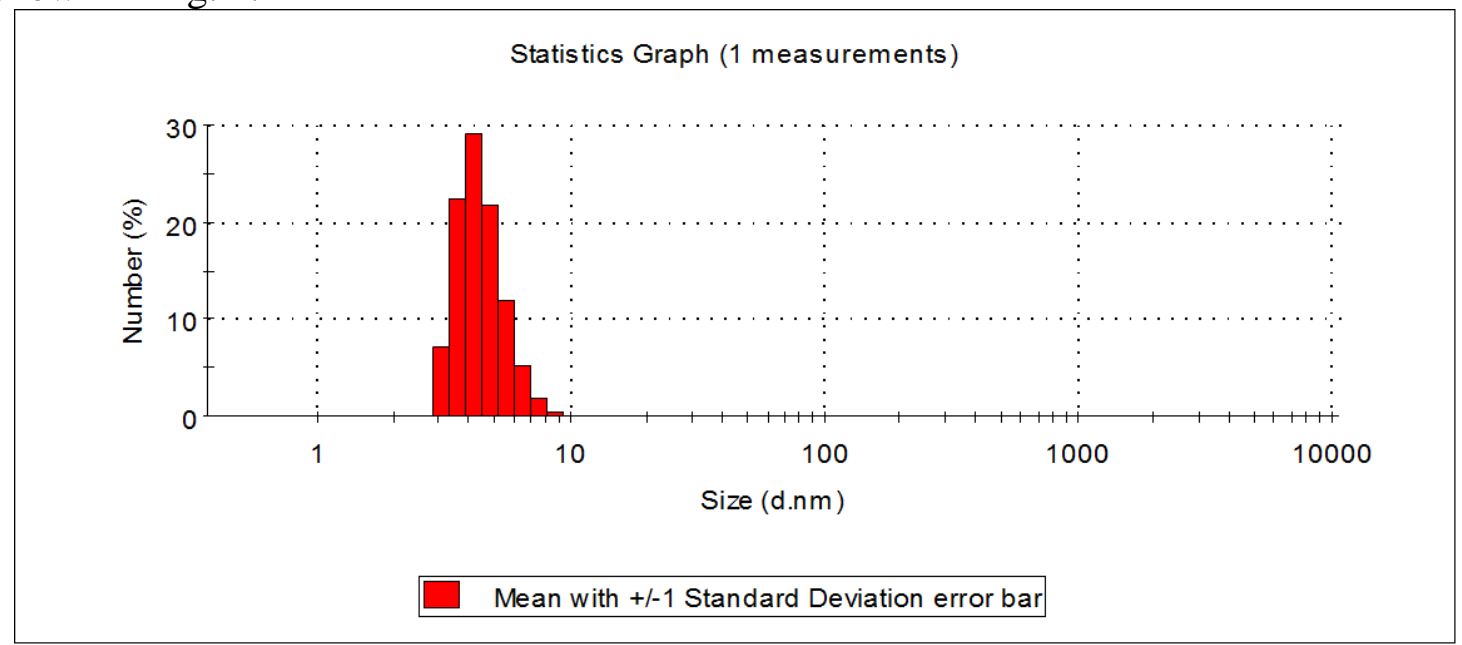

Fig. 1. Particle size of nano-silver under optimal conditions

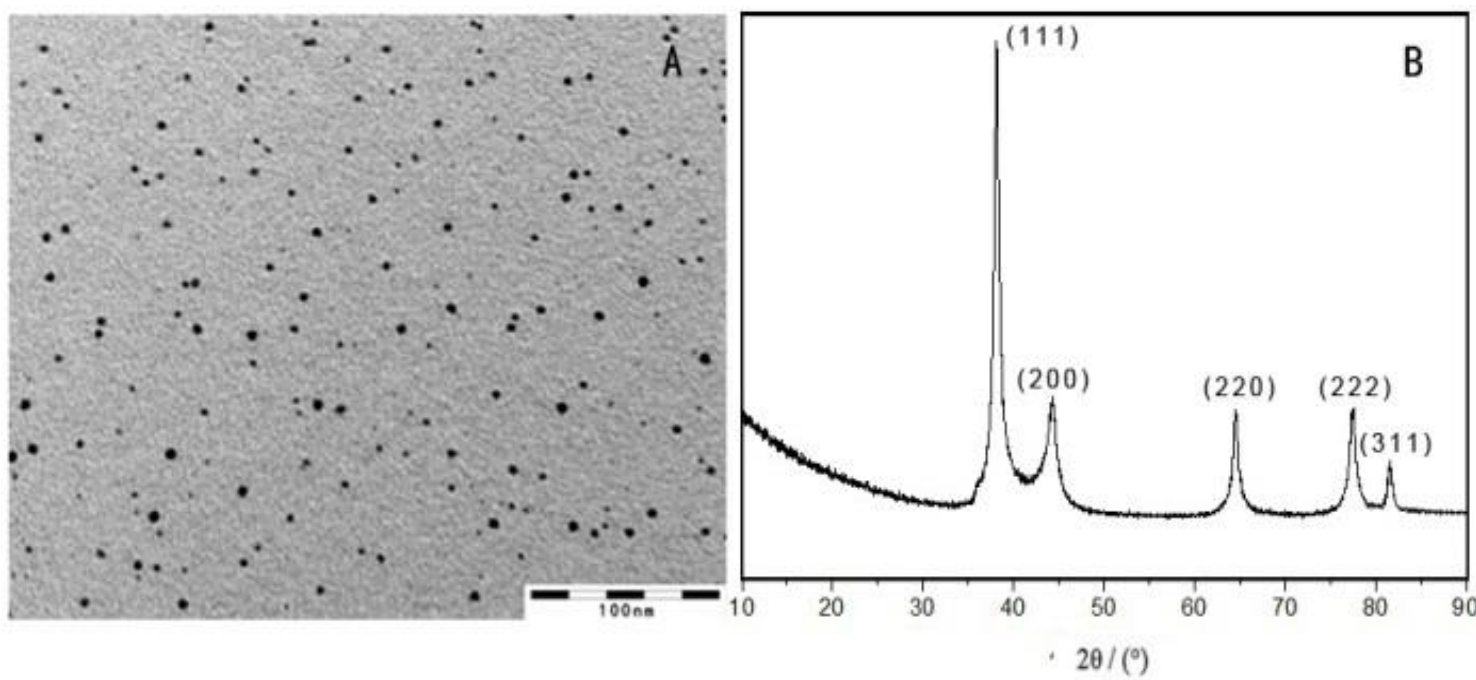

Fig. 2. TEM and XRD patterns of silver nanoparticles

The TEM and XRD patterns of nanosilver powder obtained by the optimal process were tested after centrifugal washing. The results are shown in Fig. 2.

It can be seen from Fig. 1 and Fig. 2 that the main particle size of nano-silver powder is below $10 \mathrm{~nm}$ under the optimum conditions, which is in accordance with the average particle size.

Antibacterial Test of Nano Silver Powder. The antimicrobial activity of the nano-silver powder was tested according to the procedure in the experimental method. The results are shown in Table 3 and Fig. 3.

Table 3 Effect of nano silver powder content on the diameter of inhibition zone

\begin{tabular}{|c|c|c|c|c|c|c|c|}
\hline Nano silver content [ug/mL] & 0 & 2 & 4 & 6 & 8 & 10 & 12 \\
\hline Diameter [mm] & 0 & 3 & 5 & 8 & 11 & 15 & 20 \\
\hline
\end{tabular}

Table 3 shows that nano-silver powder has obvious antibacterial effect. With the increase of nano-silver concentration, the diameter of the inhibition zone increased gradually. When the 
concentration of nano-silver increased from 0 to $12 \mathrm{ug} / \mathrm{mL}$, the diameter of the inhibition zone increased almost linearly, which indicated that with the increase of the concentration of nano-silver, the antibacterial property of the antibacterial agent was significantly affected. However, as the silver was more expensive, when the inhibition zone diameter was more than $15 \mathrm{~mm}$, a strong antibacterial effect can be obtained, so the silver concentration can be set at $10 \mathrm{ug} / \mathrm{mL}$.

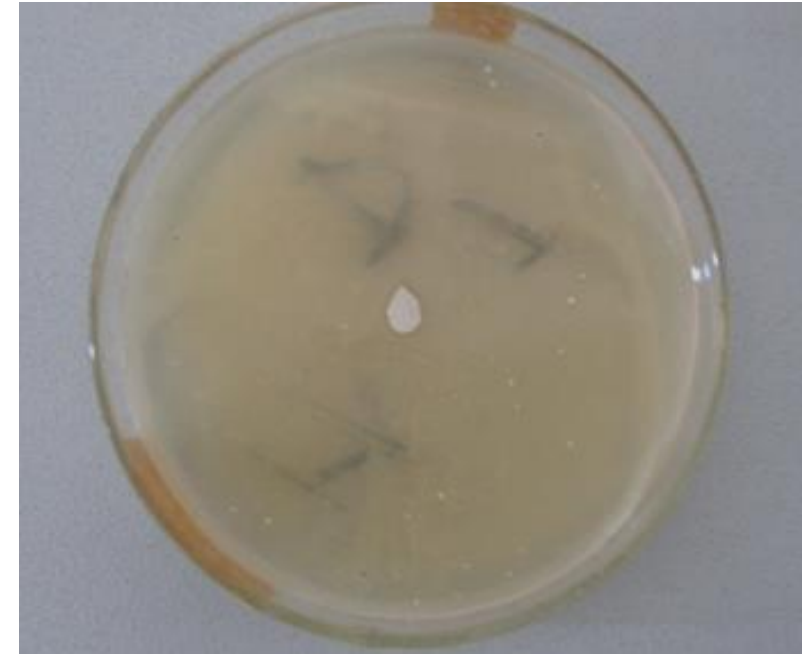

a) A blank sample with distilled water

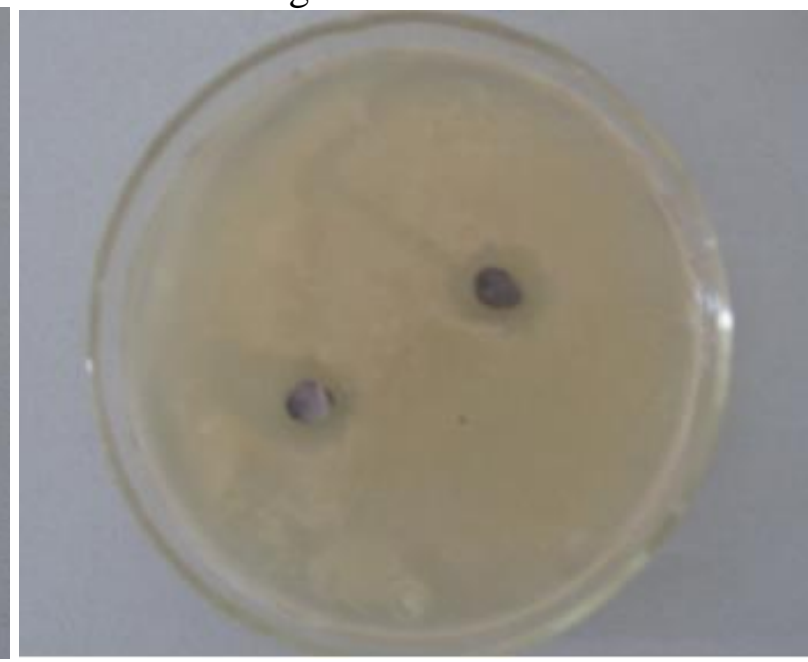

b) A sample with nano-silver powder

Fig. 3. Antibacterial effect of nano silver powder on Escherichia

Fig. 3 shows that when the concentration of nano-silver solution was $10 \mathrm{ug} / \mathrm{mL}$, the antibacterial diameter in the E. coli dish can reach $15 \mathrm{~mm}$.

\section{Summary}

The optimal process of preparation on silver nanoparticles by liquid phase reduction of silver nitrate solution was determined through orthogonal design. The optimum conditions were determined as follows: the $\mathrm{AgNO}_{3}$ concentration was $20 \mathrm{mg} / \mathrm{mL}$, the amount of polyethylene glycol 200 was $10 \mathrm{~mL}$, $\mathrm{n}\left(\mathrm{C}_{6} \mathrm{H}_{8} \mathrm{O}_{6}\right) / \mathrm{n}\left(\mathrm{AgNO}_{3}\right)$ was $1: 3$, the reaction temperature was $60{ }^{\circ} \mathrm{C}$, then nano-silver powder with particle size less than $10 \mathrm{~nm}$ can be prepared. When the concentration of the nano-silver solution was $10 \mathrm{ug} / \mathrm{mL}$, the bacteriostasis of Escherichia coli could be obtained, and the diameter of the inhibition zone could reach $15 \mathrm{~mm}$. Aseptic environmental protection material is the future development direction, the research of the paper has certain directive significance to the research and development of antibacterial material.

\section{Acknowledgement}

This research was financially supported by the Scientific and Technological Project of Henan province (142102210441).

\section{References}

[1] L.N. Cao, J.H. Qian: PACKAGING ENGINEERING Vol. 5 (2012), p. 122.

[2] G.H. Pan, Y. Li, B.S. Li: PACKAGING ENGINEERING Vol. 17 (2012), p. 130.

[3] W.W. Li, L.X. Mo, J.L. Fu: Applied Mechanics and Materials Vol. 189 (2012), p. 115.

[4] W.W. Li, L.X. Mo, J.L. Fu: Applied Mechanics and Materials Vol. 262 (2013), p. 523.

[5] J.L. Fu, Y.L. Li, L.X. Mo: Advanced Materials Research Vol. 904 (2014), p. 121.

[6] S.M. Zhang, D. Wan, Y.K. Zhang: PACKAGING ENGINEERING Vol. 13 (2015), p.47.

[7] H.S. Chen, N. Li: Paper and Paper Making Vol. 9 (2015), p. 98. 